\title{
Oxidative Stress Impairs Learning and Memory in apoE Knockout Mice
}

\author{
Marianne Evola, Allyson Hall, Trevor Wall, Alice Young, and Paula Grammas* \\ Garrison Institute on Aging, Department of Neurology and Department of Pharmacology and \\ Neurosciences Texas Tech University Health Sciences Center, Lubbock, Texas
}

\begin{abstract}
Cardiovascular risk factors, such as oxidative stress and elevated lipids, are linked to the development of cognitive impairment. A mediator common to both stressors is the apolipoprotein $\mathrm{E}$ (apoE). The objectives of this study are to determine the effects of apoE deficiency and dietinduced systemic oxidative stress in mice on vascular expression of inflammatory proteins and on cognitive function. Mice are placed on a diet enriched in homocysteine for fifteen weeks and then assessed for spatial learning using an eight-arm radial maze and for inflammatory protein expression by immunohistochemistry. Our results show that diet-induced oxidative stress does not affect cognitive function in normal mice. In contrast, apoE-/- mice on the homocysteine diet show significantly impaired $(\mathrm{p}<0.001)$ maze performance. ApoE-/- mice also have high cholesterol levels. There is no expression of inflammatory proteins IL-6 and IL-8 in the vasculature of control mice on normal or homocysteine diet and little in apoE-/- mice on normal diet. In contrast, apoE-/- mice on homocysteine diet show pronounced vascular reactivity to IL-6 and IL-8 antibodies. These data show that systemic oxidative stress correlates with expression of inflammatory proteins in the cerebral vasculature and impaired cognitive function. These results are consistent with the hypothesis that an oxidative-inflammatory cycle in the cerebral vasculature could have deleterious consequences for cognition.
\end{abstract}

\section{Keywords}

Apolipoprotein E; ApoE knockout; radial arm maze; homocysteine; cognition; oxidative stress; inflammation; cytokines

\section{Introduction}

Increasing evidence links cardiovascular-associated risk factors to the development of cognitive impairment, especially in Alzheimer's disease (AD). Both oxidative stress and elevated lipids correlate with increased risk of developing dementia (Reutens and Sachdev, 2002). A mediator common to both stressors is the lipid-carrying protein apolipoprotein $E$ (apoE). Apolipoprotein E is a vital component in lipoprotein metabolism (HirschReinshagen et al., 2009), but may also underlie biological processes and pathologic conditions independent of lipid metabolism, including $\mathrm{AD}$, cognitive function, and

\footnotetext{
*Address correspondence to: Paula Grammas, PhD, Garrison Institute on Aging, Texas Tech University Health Sciences Center, 3601 4th Street Stop 9424, Lubbock, Texas 79430, 806-743-3612 (phone), 806-743-3636 (fax), paula.grammas@ttuhsc.edu.

Publisher's Disclaimer: This is a PDF file of an unedited manuscript that has been accepted for publication. As a service to our customers we are providing this early version of the manuscript. The manuscript will undergo copyediting, typesetting, and review of the resulting proof before it is published in its final citable form. Please note that during the production process errors may be discovered which could affect the content, and all legal disclaimers that apply to the journal pertain.
} 
immunoregulation (Mahley and Rall, 2000). After liver, the highest levels of apoE expression are found in the nervous system (Boyles et al., 1985; Elshourbagy et al., 1985), supporting an important role for this protein in neural function. Inheritance of the apoE allele 4 increases the risk of developing late-onset AD (Lendon et al., 2000; Wakutani et al., 2002). Impairments in cognitive performance have been observed in aged apoE-deficient (apoE-/-) mice (Champagne et al., 2002; Grootendorst et al., 2005; Troen et al., 2006; van Meer et al., 2007; van Praag et al., 2005; Zhou et al., 1998). Absence of apoE also correlates with diminished anti-oxidative capacity in animals (Law et al., 2003). Finally, in aged mice lack of apoE has a destabilizing effect on the cerebral microcirculation leading to bloodbrain barrier leakage (Hafezi-Moghadam et al., 2007).

Consistently, studies report a correlation between cognitive function and the serum concentrations of folate (Mihalick et al., 2003; Morris, 2002), vitamin B-12 (Selhub, 1999), vitamin B-6 (Borroni et al., 2002; Miller et al., 2002), and more recently homocysteine (Auer et al., 2002; Herrmann and Knapp, 2002; Korczyn, 2002; McIlroy et al., 2002; Mizrahi et al., 2002; Nilsson et al., 2002; Nourhashemi et al., 2000; Prins et al., 2002; Reutens and Sachdev, 2002; 2005; Shea and Rogers, 2002; Sheehan and Fazel, 2002; Vermeer et al., 2002). Hyperhomocysteinemia promotes oxidative stress by increasing formation of reactive oxygen species (Papatheodorou and Weiss, 2007). The damaging effects of homocysteine may influence normal development as well as age-related decline. Addition of methionine to the diet of pregnant rats induces hyperhomocysteinemia and leads to the formation of sustained oxidative stress in the brains of progeny (Makhro et al., 2008). Newborn animals are characterized by lower body weight, cerebral superoxide dismutase deficiency, and impaired cognitive capacity. In aging, plasma levels of homocysteine are predictive of cognitive decline (Herrmann et al., 2007). Hyperhomocystemia has been implicated in the pathogenesis of neurodegenerative and neuropsychiatric disorders including AD, stroke and vascular dementia (Reutens and Sachdev, 2002; Kronenberg et al., 2009). Finally, because homocysteine can damage vascular endothelial cells (Papatheodorou and Weiss, 2007), homocysteine may contribute to the pathogenesis of CNS disorders by causing both cerebrovascular injury as well as by direct neurotoxicity.

The brain microvasculature could be a convergence point for the effects of oxidative stress and lipid injury in health and disease. In $\mathrm{AD}$, we have shown brain microvessels express oxidized proteins and release high levels, compared to control-derived vessels, of a number of inflammatory proteins including tumor necrosis factor- $\alpha(\mathrm{TNF} \alpha)$, interleukin (IL) IL-1 $\beta$, IL-6, and IL-8 (Grammas and Ovase, 2001; Grammas et al., 2006). Recent brain imaging data from humans and animals suggest that cerebrovascular dysfunction may precede cognitive decline and neurodegeneration in $\mathrm{AD}$ and $\mathrm{AD}$ animal models (Bell and Zlokovic, 2009). The effects of oxidative stress in apoE knockout mice on brain vascular inflammation and cognition are unknown.

In humans, assessment of vascular inflammation in the context of cognitive function is not possible. However, behavioral experiments in rodents can be utilized to model memory and cognitive functions, while assessing vascular inflammation. In this regard, the 8-arm radial arm maze, developed by Olton and Samuelson (1976), is a widely used measure of cognitive function that captures spatial learning and working memory in rodents (Hodges, 1996).

The objectives of this study are to determine the effects of apoE deficiency and diet-induced systemic oxidative stress in mice on vascular expression of inflammatory proteins and on cognitive function, as assessed by behavioral experiments in the radial arm maze. 


\section{Methods}

\section{Animals and diet}

Animal procedures were performed in accordance with NIH "Guide for the Care and Use of Laboratory Animals" and Texas Tech University Health Sciences Center Institutional Animal Care and Use Committee (IACUC) guidelines. Due to limited availability at the time of the study, ApoE knockout (-l-) mice were bred in our research facility. One male and three female breeders (4-6 weeks old) were purchased from Jackson laboratory (Bal Harbor, Maine 04609). ApoE (-/-) were homozygous for the ApoE ${ }^{\text {tmlUnc }}$ mutation and were bred on C57B1/6J background strain. Pregnant females were separated on day 18 of gestation and were housed with their litter until the pups were weaned at 21 days of age. Pups were then separated and housed individually. Female mice were used for breeding only; male mice were used for ongoing experiments. Male, six month old, C57B1/6J mice were purchased from Charles River Laboratories (Wilmington, MA 01887). Upon delivery, $\mathrm{C} 57 \mathrm{Bl} / 6 \mathrm{~J}$ mice were housed individually and given free access to food and water. Diet manipulations were instituted for control and apoE (-/-) mice at 7 to 8 months of age and mice were maintained on the respective diet for the duration of experiments. Both C57Bl/6J and apoE $-/-$ mice were maintained on a restricted diet of either normal rodent chow (Purina) or on 50\% of the Harlan Teklad TD97345 diet (Harlan Teklad, Madison Wisconsin) which is enriched in methionine and depleted of vitamins B6, B12 and folate to induce hyperhomocysteinemia. While on restricted diet, mice were weighed daily and chow amounts adjusted so that each mouse maintained a weight no less than $85 \%$ of its weight at the beginning of experiments. Mice were individually housed in ventilated cages with hard wood bedding and free access to water.

\section{Behavioral experiments. Apparatus}

A modular plexiglass 8 arm radial arm maze (Med. Associates Inc., St. Albans, VT) with Ethovision 3.1 video tracking software (Noldus, Wageningen, Netherlands) was used for these experiments. The central maze compartment had a diameter of 8 inches and each arm was 14 inches long with food receptacles located at the end of each arm. The maze was enclosed in a curtained area with fixed visual cues on the curtained "walls", the experimenter stationed between arms 7 and 8 and the computer stationed outside of the curtained area. The camera was mounted 4 feet above the central compartment. The maze was saturated with the odor of chocolate to minimize the use of odor cues for correct selection of baited arms by inserting chocolate chips in the ventilation holes of each arm.

\section{Procedure}

At the age of 9-10 months, after being fed the control or homocysteine (HC) diet for two months, mice were first exposed to the maze. For three sessions, mice were placed in the center of the maze and allowed to explore freely for $10 \mathrm{~min}$. Chocolate shavings were scattered throughout the maze to encourage exploration. On all subsequent sessions, only the food receptacle at the end of each arm was baited with chocolate and sessions concluded when the mouse had visited each of the 8 arms at least one time or the maximum time limit of $10 \mathrm{~min}$ had elapsed. All four paws crossing from the center compartment into an arm counted as an "entry"; an entry was correct if the arm had not been previously entered during the current session. Mice were trained daily Monday through Friday for 15 blocks of 5 sessions each. The RAM has a fixed spatial structure of a central compartment with eight radiating arms, but as each arm entry is a distinct piece of information, the number of accurate entries before an error may reflect spatial memory span (Hodges, 1996; Olton and Samuelson, 1976), a measure of visuospatial working memory (Baddeley and Hitch, 1993; Conway et al., 2005). Two measures of RAM performance are therefore reported, the total number of entries to complete the maze, which is an overall measure of learning and 
memory, and the number of correct arm entries before a re-entry error, which is suggestive of spatial memory span or working memory.

\section{Tissue Recovery and immunohistochemistry}

Mice were euthanized and brain tissue fixed by transcardial perfusion with $10 \%$ neutral buffered formalin (NBF). The brain was removed and $1 \mathrm{~mm}$ blocks of tissue from cerebral cortex were post fixed in 10\% NBF for additional $12 \mathrm{~h}$ and embedded in paraffin. Brain sections were deparaffinized in xylene, hydrated through a graded alcohol series, then rinsed for $5 \mathrm{~min}$ in deionized water and incubated for $20 \mathrm{~min}$ at room temperature with Pepsin reagent (Cat. No: PEP956 H, Biocare Medical, Concord, CA) for antigen unmasking. Sections were washed in Tris-Buffered Saline containing 0.1\% Tween-20 (TBST) (pH 7.4) for $5 \mathrm{~min}$, incubated $30 \mathrm{~min}$ in $0.3 \% \mathrm{H}_{2} \mathrm{O}_{2}$ in methanol to block endogenous peroxidase activity, washed in TBST for $5 \mathrm{~min}$, and blocked using TBST containing $2.5 \%$ normal goat serum for $20 \mathrm{~min}$ at room temperature. Sections were then incubated with rabbit polyclonal antibodies to IL-6 or IL-8 (Cat. No: ab6672; Cat. No: ab7747; Abcam, Cambridge, MA) diluted 1:250 in TBST containing $2.5 \%$ normal goat serum for $30 \mathrm{~min}$ at room temperature, washed in TBST for $5 \mathrm{~min}$, and incubated with goat anti-rabbit IgG biotinylated secondary antibody (Cat. No: GR602H, Biocare Medical, Concord, CA) for $30 \mathrm{~min}$ at room temperature. Following stringent washing with TBST for $5 \mathrm{~min}$, sections were incubated with VECTASTAIN Elite ABC reagent (Cat. No: PK-6200, Vector Laboratories, Inc., Burlingame, CA) for $30 \mathrm{~min}$ at room temperature, washed in TBST for $5 \mathrm{~min}$, incubated with diaminobenzidine (DAB) tetrahydrochloride pexoxidase substrate solution (Cat. No: D3939, Sigma, St. Louis, MO), rinsed in deionized water and counterstained with Gill's Hematoxylin. Sections were viewed using an Olympus BX50 upright viewing system and images captured using ACT-1 software (Nikon, Melville, NY).

\section{Blood collection and lipid analysis}

Blood was collected before and two months after introduction of the homocysteine-inducing or control diets. Blood was also collected immediately prior to the start of maze training via the submandibular vein using a Goldenrod Lancet. A maximum volume of $200 \mu \mathrm{l}$ was collected. Cholesterol was determined using the Cobas 6000 by the Department of Pathology at the Texas Tech University Health Sciences Center.

\section{Statistical analysis. Behavioral data analysis}

Daily data for "total number of entries" and "entries without error (span)" were collapsed into a mean of 5-day blocks for each animal. Then the mean for each "block" was averaged across animals. Data are graphed as mean "block" with standard error (SE). Performance at the start of training (i.e., block 1) was compared across groups by two-factor (mouse and diet) ANOVA. Acquisition and final performance were compared by fitting a continuous Weibull function (Gallistel et al. 2004) to the data with Prism 5.02 (GraphPad Software, San Diego California USA, www.graphpad.com). As applied to our entries versus block data, the function can be written as

$$
\text { Entries }=\text { Asymptote } *\left(1-2_{-[\text {Blocks/Latency }] S}\right) \text {, }
$$

where Asymptote is an estimate of the final level of performance at infinite time, Latency is an estimate of how long it took for asymptotic performance to appear, and $\mathrm{S}$ is an estimate of the abruptness of change in performance. The Weibull function fits were used to estimate the predicted entries at block 15, and a common fit for all groups was compared to a separate fit for each group (control/normal diet, control/HC, apoE-/-/normal diet, and apoE 
$-/-/ \mathrm{HC}$ ) by $F$ test. Significant differences between groups were reflected in non-overlap of $95 \%$ confidence limits.

\section{Lipid analysis}

The mean and SE for each group (Strain/Diet) was calculated at the two time points that blood was collected. A two-factor ANOVA for repeated measures was used to assess significant differences between groups and across time (Baseline and 2 month). Bonferroni corrections for pairwise comparisons was used to test for significant differences among control mice, control mice on homocysteine diet, apoE-/-, apoE-/- on homocysteine diet.

\section{Results}

Analysis of blood lipids in control and apoE-/- mice showed that baseline total cholesterol was significantly elevated in apoE-/- mice compared to levels in control mice (Fig. 1). Placement of animals on the homocysteine diet for 2 months did not affect total cholesterol levels in either group (Fig. 1). At the start of experiments (block 1), groups did not differ with regard to accuracy of maze performance $(p=0.14)$. However, as training progressed, the level of performance dissociated across groups. Control C57Bl/6J mice progressively improved their performance on the radial arm maze during the first five blocks of assessment. At block 15, control mice efficiently completed the maze such that the total number of entries was 9.9 with 6.7 arms entered without error (Fig. 2a,b). In control mice, the homocysteine diet did not affect accuracy (Fig. 2a,b) as asymptote for total entries was 9.4 with 6.6 arms entered before error. In contrast, although apoE-/- mice also showed improvement during the first 5 blocks of training, their performance stabilized at only 11.9 total entries with 5.5 arms entered without error; significantly $(p<0.001)$ worse than control mice as demonstrated by non-overlap of confidence intervals (Table 1). Furthermore, apoE $-1-$ mice that were maintained on homocysteine diet displayed even lower accuracy than knock-out mice on normal rodent chow (Fig. 2a, b). The former mice showed no improvement during the first five blocks of training, and their performance stabilized at 14.3 total arm entries with only 4.5 arms entered without error; significantly $(\mathrm{p}<0.001)$ worse than apoE-/- mice on normal diet (Table 1).

At the conclusion of behavioral experiments, brains were processed for immunohistochemical examination. Sections from control and apoE-/- mice were examined for the presence of inflammatory cytokines, IL-6 and IL-8, in brain vessels. There was no expression of inflammatory proteins IL- 6 and IL-8 in the vasculature of control mice on normal or homocysteine diet (Figs. 3a, b; 4a, b) and little in apoE-/- mice on normal diet (Figs. 3c and 4c). In contrast, the cerebromicrovasculature of apoE-/- mice on homocysteine diet shows pronounced reactivity to IL-6 and IL-8 antibodies (Fig. $3 \mathrm{~d}$ and 4d).

\section{Discussion}

ApoE knockout mice are a widely used model of hypercholesterolemia. These animals, on standard chow diet, spontaneously develop atherosclerosis and have total cholesterol levels in excess of $500 \mathrm{mg} / \mathrm{dL}$ (Meir and Leitersdorf, 2004). In the current study, these animals demonstrate high cholesterol levels and show modest impairment of cognitive function. These data are consistent with a body of literature that demonstrates a link between hypercholesterolemia and brain function. In a cholesterol-fed rabbit model of human coronary heart disease there is production and accumulation of amyloid beta (A $\beta$ ) in the brain (Sparks et al., 2000). Similarly, a high-fat/high cholesterol diet increases $A \beta$ deposition in a transgenic mouse model of $\mathrm{AD}$ (Refolo et al., 2000). In humans increased prevalence of $\mathrm{AD}-$ like $\mathrm{A} \beta$ deposits in the neuropil and within neurons occurs in the brains of nondemented individuals with heart disease and a decreased prevalence has been observed in 
the patients on cholesterol-lowering statins (Wolozin et al., 2000). It should be noted that in the current study, placement of apoE-/- mice on homocysteine diet does not further increase cholesterol levels. Results of the current study add to a growing literature suggesting that life-style factors can influence cognition. A systematic review of 18 prospective studies shows consistent associations between high midlife total cholesterol levels and the development of AD dementia in later life (Anstey et al., 2008; HirschReinshagen et al., 2009). Interestingly, there is no evidence supporting an association between late-life cholesterol levels and dementia. Combined, these data suggest that in humans chronic or long-term lipid stress may be necessary to induce cognitive impairments. In the current study, we find the apoE- $-1-$ mice, an animal model characterized by hyperlipidemia, demonstrate a modest impairment of cognitive function. In contrast, our results show that apoE- $-1-$ mice on the homocysteine diet demonstrate a highly significant impairment ( $\mathrm{p}<0.001)$ in maze performance compared to control mice on the homocysteine diet. These data support the idea that changes in cognition likely result from the interaction of multiple cardiovascular risk factors. In this regard, a recent review of all studies in Pubmed from 2000 to 2007 (Purnell et al., 2009) that analyzed the association of cardiovascular risk factors and the development of AD shows that no single clinically defined cardiovascular risk factor is significantly associated with $\mathrm{AD}$ but rather the strength of the association of cardiovascular risk factors and $\mathrm{AD}$ is greatly enhanced by interactions between factors.

Another variable that is likely to influence the effect of cardiovascular risk factors on cognition is the duration of behavioral observation. In the current study, homocysteineinduced oxidative stress alone was unable to alter cognitive function in C57B1/6J mice examined during the 15 block period (Fig 2a,b,). It was only in the already impaired apoE-/ - mice that homocysteine exacerbated the cognitive impairment. Similarly, patients with mild cognitive impairment (MCI) express vascular risk factors, including homocysteine, significantly more often than controls. However, only age and hypertension, but not hyperhomocysteinemia, influence progression to dementia in the MCI group when assessed within a one year time period (Siuda et al., 2009;Reitz et al., 2009). The ability to demonstrate homocysteine-induced cognitive deficits may also depend on study design. A study examining the effects of homocysteinemia on spatial learning in young apoE-/- mice using the Morris water maze finds that although diet stress has no impact on watermaze acquisition in apoE-/- mice compared to controls, it does produce marked deficits in reversal learning, when the escape platform is moved to a new location (Troen et al., 2006). In contrast, Zhou et al. (1998) demonstrate that young apoE-/- mice require more trials to learn watermaze than do controls, and that restraint stress exacerbates cognitive deficits so that apoE $-/-$ mice do not find the escape platform in three days of training. Zhou's data are similar to the pattern revealed in the current study (Fig. 2a,b). ApoE-/- mice exhibit only limited improvement in the RAM compared to control mice, and performance stabilized at markedly lower levels, suggesting learning impairment. In contrast, our apoE-/- mice on $\mathrm{HC}$ diet show no sign of learning over 15 blocks of training.

The type and duration of stress may also impact cognition. In this regard, exposure of 4-5 month old apoE-/- mice to chronic rat stress ( 7 days, 1-2 hrs/day) improves watermaze acquisition, compared to wild-type mice (Grootendorst et al., 2005). These results are in sharp contrast to the impaired performance of apoE-/- mice when exposed to restraint stress ( 2 days, $20 \mathrm{~min} /$ day) (Zhou et al., 1998). However, as both the type of stress and the duration of exposure to stress differed in these studies, as did exposure to diet stress in our study (15+ blocks), any of these differences could account for the differing results. It should also be noted that compared to our studies, the above studies utilized younger apoE- $-1-$ mice to demonstrate stress-induced cognitive changes. Our results extend this work by demonstrating that the stress of the HC diet manipulation was not overcome by multiple 
weeks of additional practice. Equally notable is the impaired "spatial working memory" of apoE $-/-/ \mathrm{HC}$ mice compared to controls (Fig. 2a,b). The range of entries prior to making a first error was markedly lower in apoE-/-/HC mice (4.5) as compared to the control/HC mice (6.6). What is equally interesting is the stability of this measure of spatial memory, during block 1 the mean "spatial span" of apoE-/-/HC mice was 4.4 (S.E. 0.47) and after 15 blocks of training "memory span" did not change. Therefore, a diminished capacity for visuospatial information may be a major contributing factor to the significant and persistent overall impairment of working memory (Fig. 2a,b).

Age may be an important modulator of apoE effects. A study in apoE-/- mice shows that aged but not young animals exhibit significantly higher nitric oxide synthase (NOS) activity levels (Law et al., 2003). This is important because nitric oxide (NO) is a neurosignaling molecule with significant roles in cognition and NO has also been implicated in neurodegenerative diseases due to its oxidative properties. These findings suggest that increased NOS activity may contribute to cognitive impairments in aged wild-type and apoE $-1-$ mice due to excess accumulation of oxidative damage in areas involved in learning and memory. Our previous work showing elevated levels of NO in the cerebral microcirculation in AD (Dorheim et al., 1994) further suggests that vascular oxidative stress is associated with impaired cognition.

Oxidative stress appears to be a common denominator underlying endothelial dysfunction. In $\mathrm{AD}$, homocysteine is thought to promote endothelial dysfunction and oxidative stress and has also been implicated in the pathogenesis of AD by data showing that serum HC levels are significantly higher in AD patients that controls (McIlroy et al., 2002; Reutens and Sachdev, 2002). The results of this study are the first to document an association between increased vascular expression of inflammatory cytokines (IL-6, IL-8) and cognition. Although analysis of inflammatory expression by immunohistochemistry is not quantitative, our results clearly show a pronounced increase in vascular IL-6 and IL-8 in apoE-/- mice on homocysteine diet. Our data demonstrate a correlation among systemic oxidative stress, expression of inflammatory proteins in the cerebral vasculature, and cognitive dysfunction. These results, along with previous work showing that the cerebral vasculature is a source for inflammatory proteins and reactive oxygen species, dsuggest that a noxious oxidativeinflammatory cycle in the vasculature could have deleterious consequences for brain function and cognition.

\section{Acknowledgments}

Sources of support: This work was supported in part by grants from the National Institutes of Health (AG15964, AG020569 and AG028367). Dr. Grammas is the recipient of the Shirley and Mildred Garrison Chair in Aging. The authors gratefully acknowledge the secretarial assistance of Terri Stahl.

\section{References}

Anstey KJ, Lipnicki DM, Low LF. Cholesterol as a risk factor for dementia and cognitive decline: a systematic review of prospective studies with meta-analysis. Am J Geriatr Psychiatry 2008;16:34354. [PubMed: 18448847]

Auer J, Berent R, Eber B. Homocysteine and dementia. N Engl J Med 2002;346:476-83. [PubMed: 11844848]

Baddeley AD, Hitch G. The recency effect: implicit learning with explicit retrieval? Mem Cognit 1993;21:146-55.

Bell RD, Zlokovic BV. Neurovascular mechanisms and blood-brain barrier disorder in Alzheimer's disease. Acta Neuropathol 2009;118:103-13. [PubMed: 19319544]

Borroni B, Agosti C, Panzali AF, Di Luca M, Padovani A. Homocysteine, vitamin B6, and vascular disease in patients with AD. Neurology 2002;59:1475. author reply 1475-6. [PubMed: 12427917] 
Boyles JK, Pitas RE, Wilson E, Mahley RW, Taylor JM. Apolipoprotein E associated with astrocytic glia of the central nervous system and with nonmyelinating glia of the peripheral nervous system. $\mathrm{J}$ Clin Invest 1985;76:1501-13. [PubMed: 3932467]

Champagne D, Dupuy JB, Rochford J, Poirier J. Apolipoprotein E knockout mice display procedural deficits in the Morris water maze: analysis of learning strategies in three versions of the task. Neuroscience 2002;114:641-54. [PubMed: 12220566]

Conway AR, Kane MJ, Bunting MF, Hambrick DZ, Wilhelm O, Engle RW. Working memory span tasks: A methodological review and user's guide. Psychon Bull Rev 2005;12:769-86. [PubMed: 16523997]

Dorheim MA, Tracey WR, Pollock JS, Grammas P. Nitric oxide is elevated in Alzheimer's brain microvessels. Biochem Biophys Res Comm 1994;205:659-65. [PubMed: 7528015]

Elshourbagy NA, Liao WS, Mahley RW, Taylor JM. Apolipoprotein E mRNA is abundant in the brain and adrenals, as well as in the liver, and is present in other peripheral tissues of rats and marmosets. Proc Natl Acad Sci U S A 1985;82:203-7. [PubMed: 3918303]

Gallistel CR, Fairhurst S, Balsam P. The learning curve: implications of a quantitative analysis. Proc Natl Acad Sci U S A 2004;101:13124-31. [PubMed: 15331782]

Grammas P, Ovase R. Inflammatory factors are elevated in brain microvessels in Alzheimer's disease. Neurobiol Aging 2001;22:837-42. [PubMed: 11754990]

Grammas P, Ghatreh-Samany P, Thirmangalakudi L. Thrombin and Inflammatory proteins are elevated in Alzheimer's disease microvessels: Implications for disease pathogenesis. J Alz Dis 2006;9:51-8.

Grootendorst J, Bour A, Vogel E, Kelche C, Sullivan PM, Dodart JC, et al. Human apoE targeted replacement mouse lines: h-apoE4 and h-apoE3 mice differ on spatial memory performance and avoidance behavior. Behav Brain Res 2005;159:1-14. [PubMed: 15794991]

Hafezi-Moghadam A, Thomas KL, Wagner DD. ApoE deficiency leads to a progressive agedependent blood-brain barrier leakage. Am J Physiol Cell Physiol 2007;292:C1256-62. [PubMed: 16870825]

Herrmann W, Herrmann M, Obeid R. Hyperhomocysteinemia: a critical review of old and new aspects. Curr Drug Metab 2007;8:17-31. [PubMed: 17266521]

Herrmann W, Knapp JP. Hyperhomocysteinemia: a new risk factor for degenerative diseases. Clin Lab 2002;48:471-81. [PubMed: 12389706]

Hirsch-Reinshagen V, Burgess BL, Wellington CL. Why lipids are important for Alzheimer disease? Mol Cell Biochem 2009;326:121-9. [PubMed: 19116777]

Hodges H. Maze procedures: the radial-arm and water maze compared. Brain Res Cogn Brain Res 1996;3:167-81. [PubMed: 8806020]

Korczyn AD. Homocysteine, stroke, and dementia. Stroke 2002;33:2343-4. [PubMed: 12364715]

Kronenberg G, Colla M, Endres M. Folic acid, neurodegenerative and neuropsychiatric disease. Curr Mol Med 2009;9:315-23. [PubMed: 19355913]

Law A, Gauthier S, Quirion R. Alteration of nitric oxide synthase activity in young and aged apolipoprotein E-deficient mice. Neurobiol Aging 2003;24:187-90. [PubMed: 12493565]

Lendon CL, Han BH, Salimi K, Fagan AM, Behrens MI, Muller MC, Holtzman DM. No effect of apolipoprotein $\mathrm{E}$ on neuronal cell death due to excitotoxic and apoptotic agents in vitro and neonatal hypoxic ischaemia in vivo. Eur J Neurosci 2000;12:2235-42. [PubMed: 10947802]

Mahley RW, Rall SC Jr. Apolipoprotein E: far more than a lipid transport protein. Annu Rev Genomics Hum Genet 2000;1:507-37. [PubMed: 11701639]

Makhro AV, Mashkina AP, Solenaya OA, Trunova OA, Kozina LS, Arutyunian AV, et al. Prenatal hyperhomocysteinemia as a model of oxidative stress of the brain. Bull Exp Biol Med 2008;146:33-5. [PubMed: 19145343]

McIlroy SP, Dynan KB, Lawson JT, Patterson CC, Passmore AP. Moderately elevated plasma homocysteine, methylenetetrahydrofolate reductase genotype, and risk for stroke, vascular dementia, and Alzheimer disease in Northern Ireland. Stroke 2002;33:2351-6. [PubMed: 12364720]

Meir KS, Leitersdorf E. Atherosclerosis in the apolipoprotein-E-deficient mouse: a decade of progress. Arterioscler Thromb Vasc Biol 2004;24:1006-14. [PubMed: 15087308] 
Mihalick SM, Ortiz D, Kumar R, Rogers E, Shea TB. Folate and vitamin E deficiency impair cognitive performance in mice subjected to oxidative stress: differential impact on normal mice and mice lacking apolipoprotein E. Neuromolecular Med 2003;4:197-202. [PubMed: 14716026]

Miller JW, Green R, Mungas DM, Reed BR, Jagust WJ. Homocysteine, vitamin B6, and vascular disease in AD patients. Neurology 2002;58:1471-5. [PubMed: 12034781]

Mizrahi EH, Jacobsen DW, Friedland RP. Plasma homocysteine: a new risk factor for Alzheimer's disease? Isr Med Assoc J 2002;4:187-90. [PubMed: 11908260]

Morris MS. Folate, homocysteine, and neurological function. Nutr Clin Care 2002;5:124-32. [PubMed: 12134567]

Nilsson K, Gustafson L, Hultberg B. Relation between plasma homocysteine and Alzheimer's disease. Dement Geriatr Cogn Disord 2002;14:7-12. [PubMed: 12053126]

Nourhashemi F, Gillette-Guyonnet S, Andrieu S, Ghisolfi A, Ousset PJ, Grandjean H, et al. Alzheimer disease: protective factors. Am J Clin Nutr 2000;71:643S-49S. [PubMed: 10681273]

Olton DS, Samuelson RJ. Remembrance of places passed: Spatial memory in rats. J Exp Psychol: Animal Behav Process 1976;2:97-115.

Papatheodorou L, Weiss N. Vascular oxidant stress and inflammation in hyperhomocysteinemia. Antioxid Redox Signal 2007;9:1941-58. [PubMed: 17822365]

Prins ND, Den Heijer T, Hofman A, Koudstaal PJ, Jolles J, Clarke R, et al. Homocysteine and cognitive function in the elderly: the Rotterdam Scan Study. Neurology 2002;59:1375-80. [PubMed: 12427887]

Purnell C, Gao S, Callahan CM, Hendrie HC. Cardiovascular risk factors and incident Alzheimer disease: a systematic review of the literature. Alzheimer Dis Assoc Disord 2009;23:1-10. [PubMed: 18703981]

Refolo LM, Pappolla MA, Malester B, LaFrancois J, Bryant-Thomas T, Wang R, et al. Hypercholesterolemia accelerates the Alzheimer's amyloid pathology in a transgenic mouse model. Neurobiol Dis 2000;7:321-31. [PubMed: 10964604]

Reitz C, Tang MX, Miller J, Green R, Luchsinger JA. Plasma homocysteine and risk of mild cognitive impairment. Dement Geriatr Cogn Disord 2009;27:11-7. [PubMed: 19088473]

Reutens S, Sachdev P. Homocysteine in neuropsychiatric disorders of the elderly. Int J Geriatr Psychiatry 2002;17:859-64. [PubMed: 12221661]

Selhub J. Homocysteine metabolism. Annu Rev Nutr 1999;19:217-46. [PubMed: 10448523]

Shea TB, Rogers E. Homocysteine and dementia. N Engl J Med 2002;346:2007. author reply 2008. [PubMed: 12075065]

Sheehan B, Fazel S. Elevated plasma total homocysteine increased the risk of dementia in the elderly. Evid Based Ment Health 2002;5:126. [PubMed: 12440468]

Siuda J, Gorzkowska A, Patalong-Ogiewa M, Krzystanek E, Czech E, Wiechula B, et al. From mild cognitive impairment to Alzheimer's disease - influence of homocysteine, vitamin B12 and folate on cognition over time: results from one-year follow-up. Neurol Neurochir Pol 2009;43:321-9. [PubMed: 19742390]

Sparks DL, Martin TA, Gross DR, Hunsaker JC III. Link between heart disease, cholesterol, and Alzheimer's disease: a review. Microsc Res Tech 2000;50:287-90. [PubMed: 10936882]

Troen AM, Shukitt-Hale B, Chao WH, Albuquerque B, Smith DE, Selhub J, et al. The cognitive impact of nutritional homocysteinemia in apolipoprotein-E deficient mice. J Alzheimers Dis 2006;9:381-92. [PubMed: 16917146]

van Meer P, Acevedo S, Raber J. Impairments in spatial memory retention of GFAP-apoE4 female mice. Behav Brain Res 2007;176:372-5. [PubMed: 17126420]

van Praag H, Shubert T, Zhao C, Gage FH. Exercise enhances learning and hippocampal neurogenesis in aged mice. J Neurosci 2005;25:8680-5. [PubMed: 16177036]

Vermeer SE, van Dijk EJ, Koudstaal PJ, Oudkerk M, Hofman A, Clarke R, et al. Homocysteine, silent brain infarcts, and white matter lesions: The Rotterdam Scan Study. Ann Neurol 2002;51:285-9. [PubMed: 11891822]

Wakutani Y, Kowa H, Kusumi M, Yamagata K, Wada-Isoe K, Adachi Y, et al. Genetic analysis of vascular factors in Alzheimer's disease. Ann N Y Acad Sci 2002;977:232-8. [PubMed: 12480755] 
Wolozin B, Kellman W, Ruosseau P, Celesia GC, Siegel G. Decreased prevalence of Alzheimer disease associated with 3-hydroxy-3-methylglutaryl coenzyme A reductase inhibitors. Arch Neurol 2000;57:1439-1443. [PubMed: 11030795]

Zhou Y, Elkins PD, Howell LA, Ryan DH, Harris RB. Apolipoprotein-E deficiency results in an altered stress responsiveness in addition to an impaired spatial memory in young mice. Brain Res 1998;788:151-9. [PubMed: 9554991] 


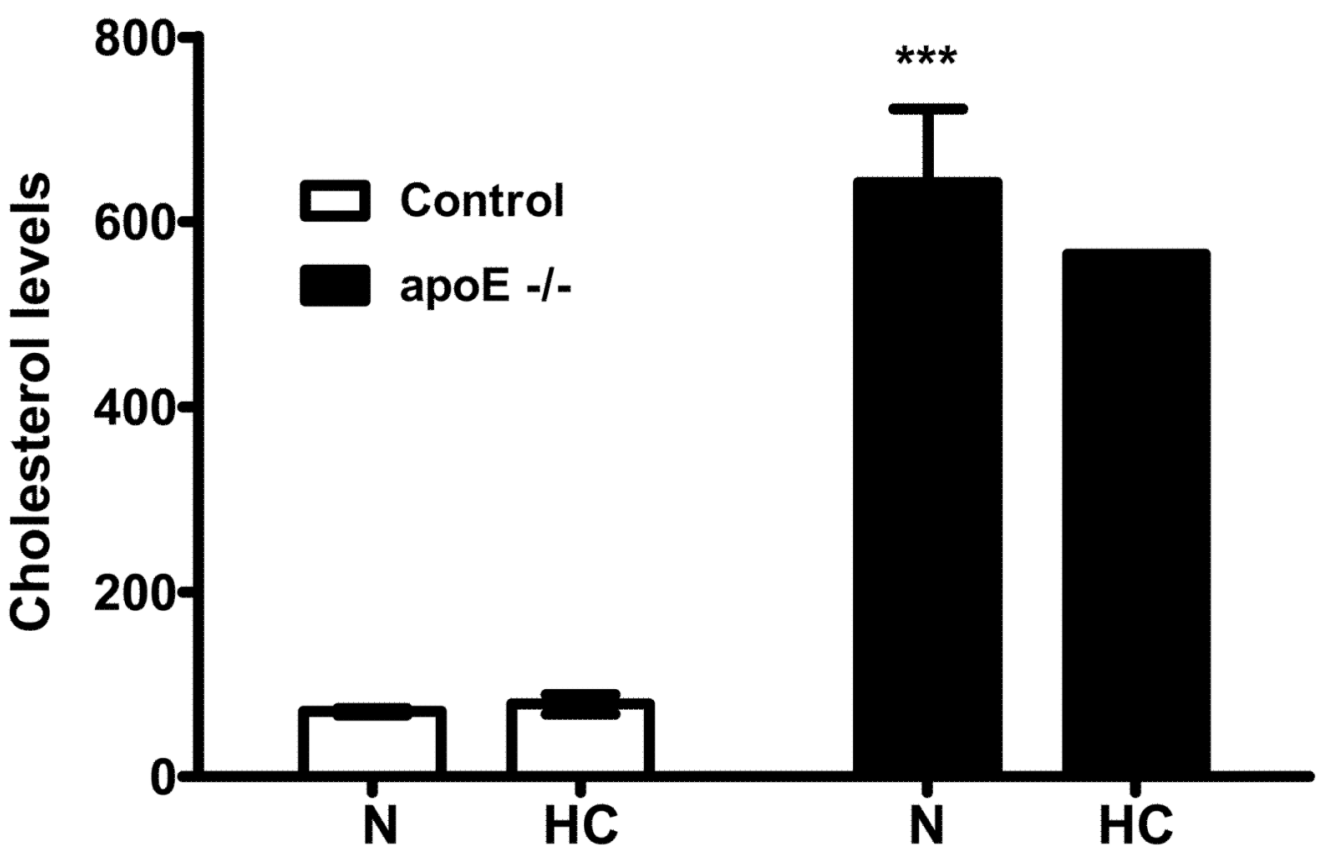

Figure 1.

Comparison of cholesterol levels for Control (C57Bl/6J) and apoE-/- mice fed normal (N) or homocysteine $(\mathrm{HC})$ diet for two weeks. ApoE-/- mice have significantly $(\mathrm{p}<0.001)$ higher cholesterol than control mice. Cholesterol levels remain consistent after being fed their respective diets for two months. ${ }^{* * *} \mathrm{p}<0.001 \mathrm{vs}$. control mice 


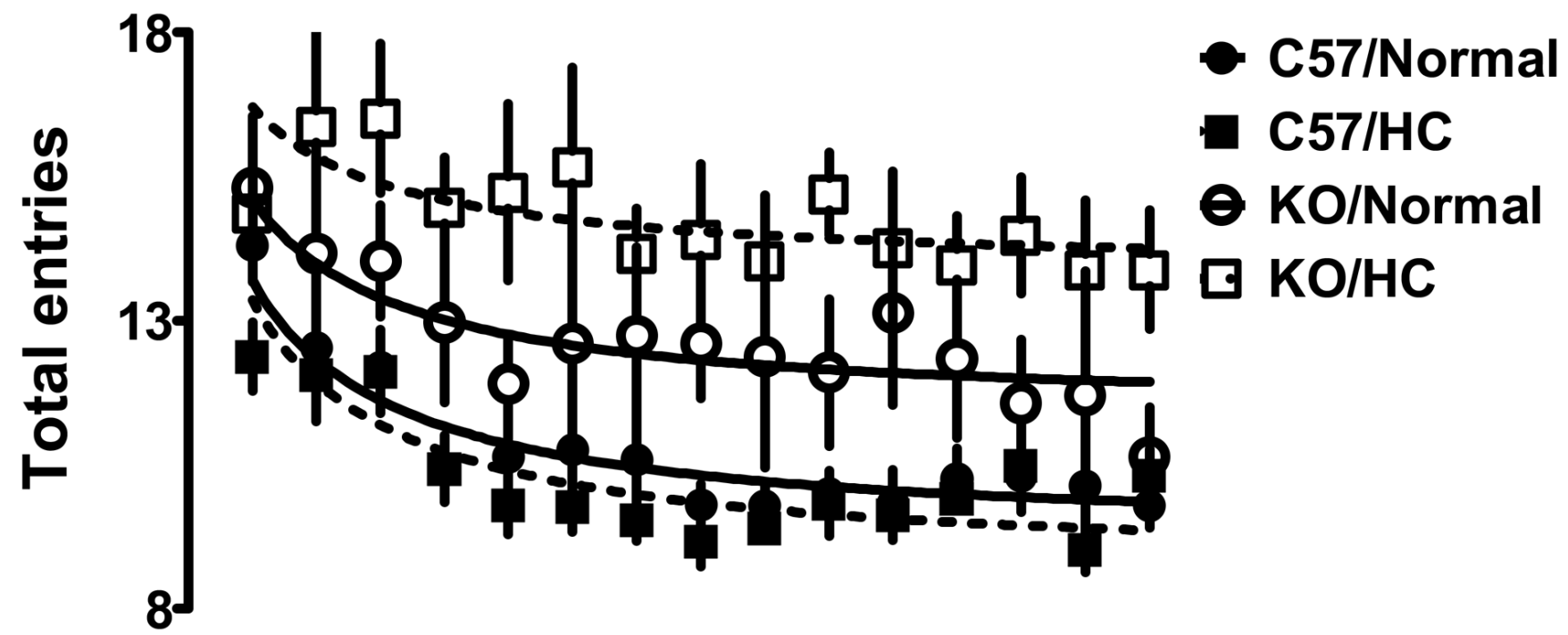

Figure 2a.

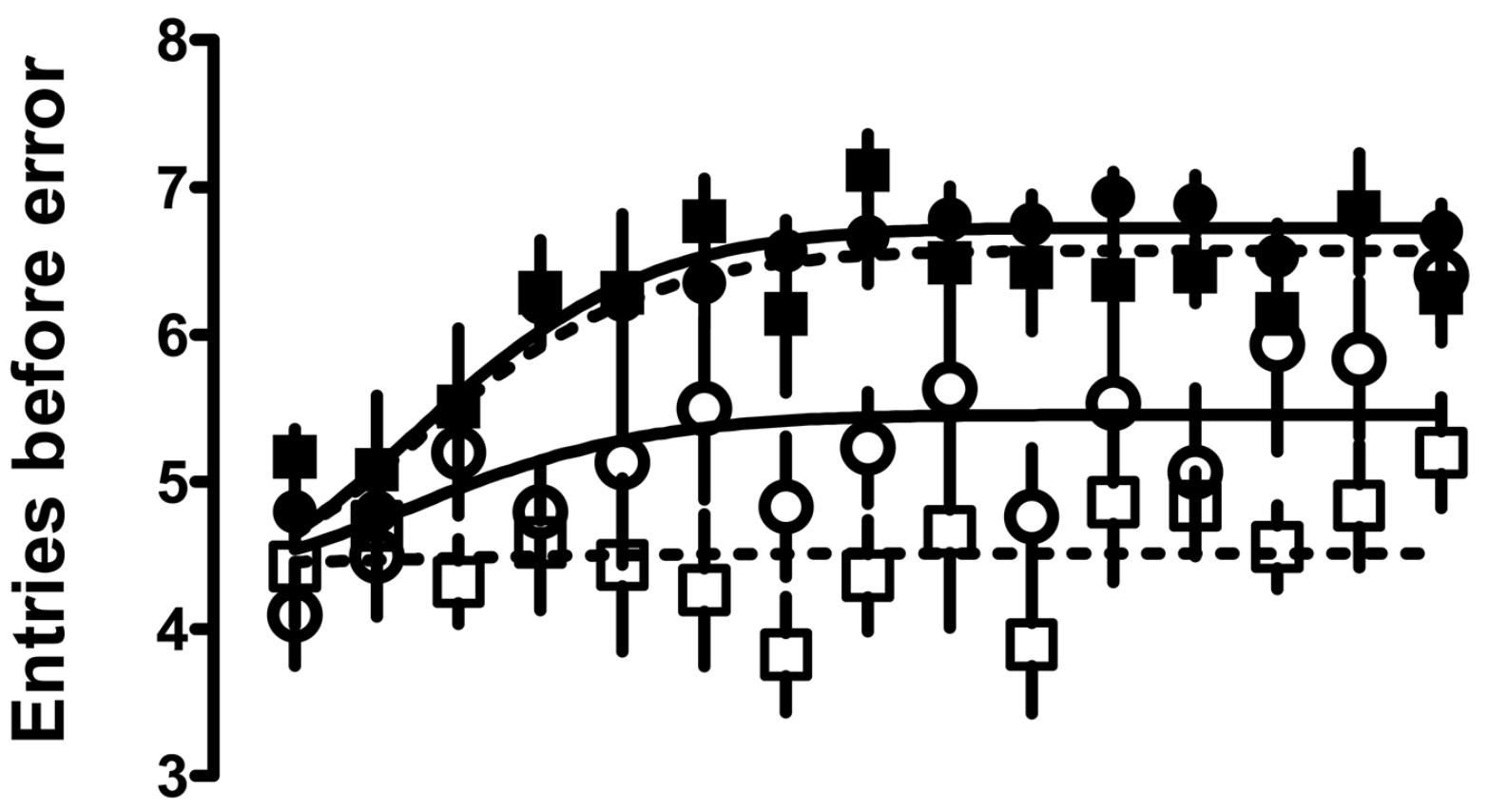

Figure 2b.

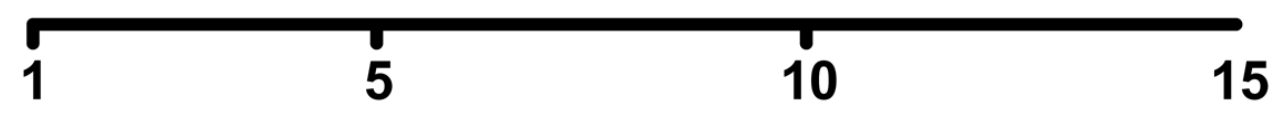

5-session blocks

Figure 2. 
a and b. Two measures of RAM performance. Y-axis for graph A shows RAM performance as measured by the total number of arm entries before all eight arms were entered ("working memory"). Y-axis for graph B shows RAM performance as measured by total number of correct entries before a re-entry error ("spatial span"). Note: Perfect performance for both measures of performance is 8 entries, however "worse" performance is demonstrated as greater than 8 entries in graph 2a and lesser than 8 in graph $2 b$. Diet does not alter accuracy of $\mathrm{C} 57 \mathrm{Bl} / 6 \mathrm{~J}$ mice on either measure of maze performance. ApoE-/- on normal diet are consistently less accurate than control mice on both measures of performance. ApoE-/mice on $\mathrm{HC}$ diet perform significantly and consistently worse than ApoE-/- mice on normal diet and $\mathrm{C} 57 \mathrm{Bl} / 6 \mathrm{~J}$ mice on both measures of RAM performance. 

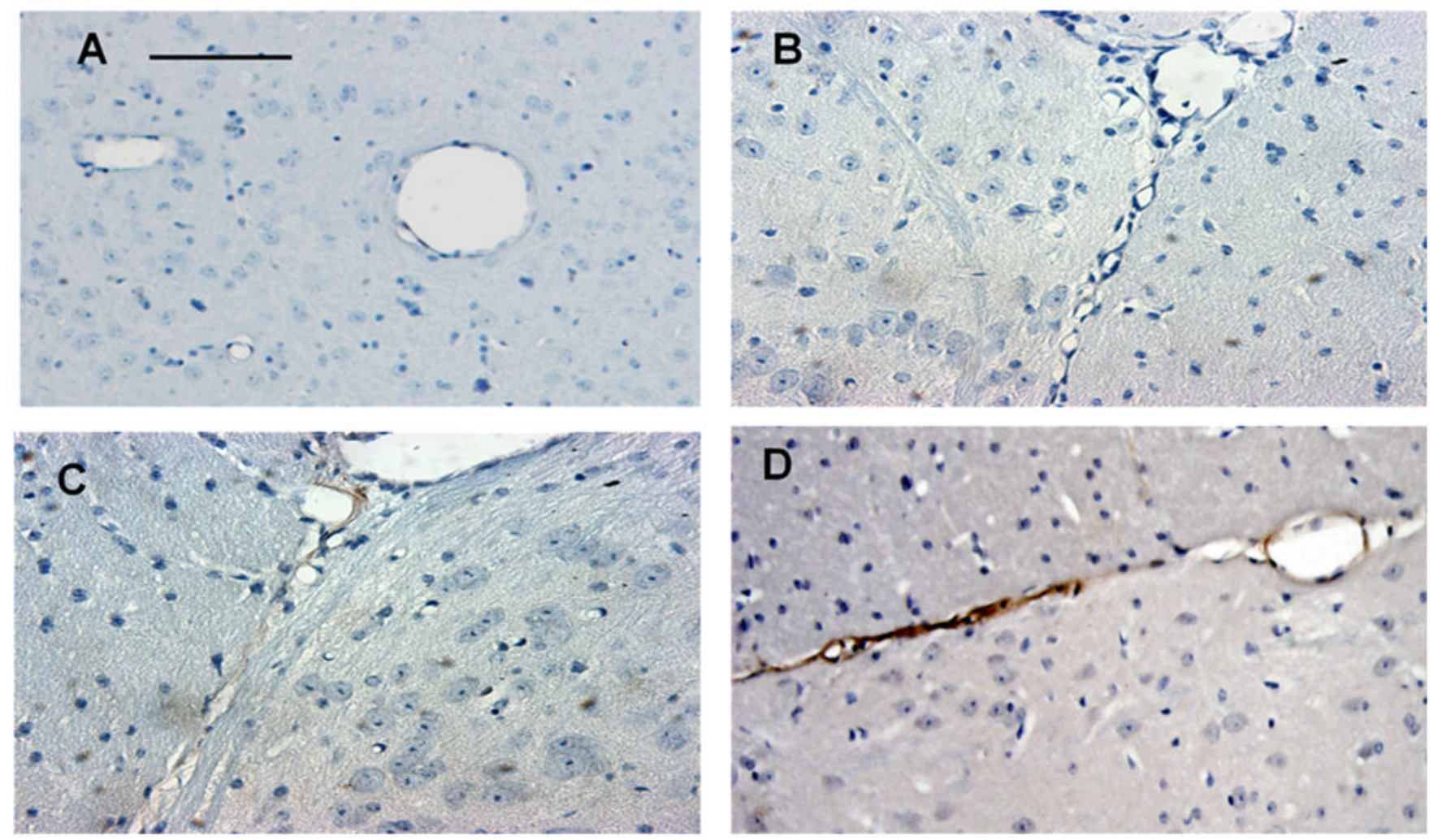

Figure 3.

Control $(\mathrm{a}, \mathrm{b})$ and apoE-/- (c,d) mice brain sections were examined by immunohistochemistry for the presence of IL-6 (20X). Staining for IL-6 was not detectable in either control mice on normal diet (a) or control mice on homocysteine diet (b). In contrast, reactivity to the IL-6 antibody (brown HRP staining) was faint in sections from apoE-/- mice on control diet (c) and strongly expressed around blood vessels in apoE-/mice on homocysteine diet (d). Bar $=20 \mu \mathrm{m}$. 

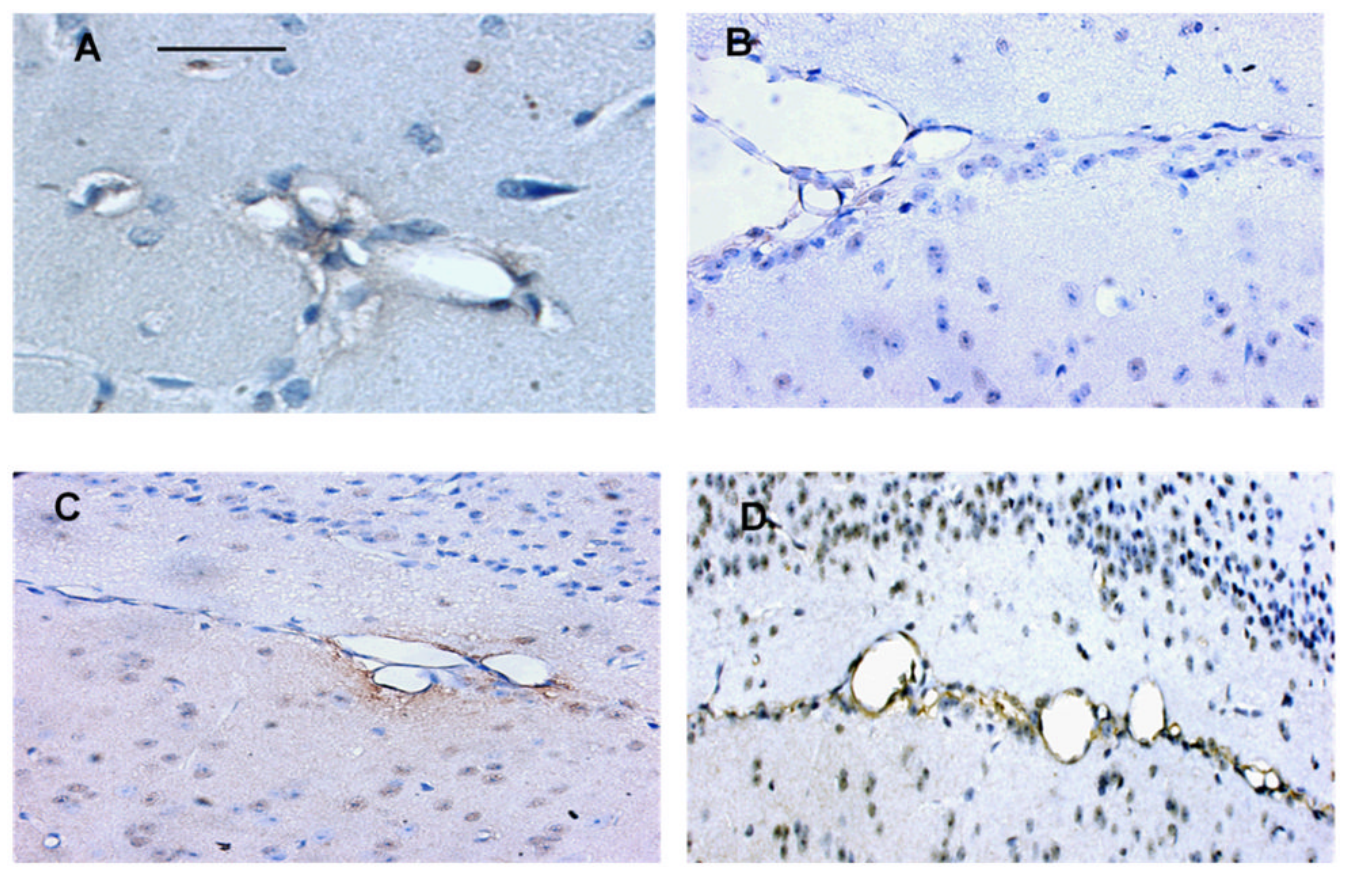

Figure 4.

Control (a, b) and apoE-/- (c,d) mice brain sections were examined by immunohistochemistry for the presence of IL-8 (20X). Staining for IL-8 was not detectable in either control mice on normal diet (a) or control mice on homocysteine diet (b). In contrast, reactivity to the IL-8 antibody (brown HRP staining) was faint in sections from apoE-/- mice on control diet (c) and strongly expressed around blood vessels in apoE-/mice on homocysteine diet (d). Bar $=20 \mu \mathrm{m}$. 
Table 1

RAM Performance

\begin{tabular}{|l|l|l|}
\hline & Total arm entries Mean 95\% CI & Arm entries without error Mean 95\% CI \\
\hline C57B1/6J - Normal & $9.9(9.3-10.4)$ & $6.7(6.5-6.9)$ \\
\hline C57B1/6J - HC & $9.4(8.7-10.0)$ & $6.6(6.3-6.8)$ \\
\hline apoE -/- Normal & $11.9(11.3-12.6)$ & $5.5(5.2-5.7)$ \\
\hline apoE -/- HC & $14.3(13.6-14.9)$ & $4.5(4.3-4.8)$ \\
\hline
\end{tabular}

Differences in RAM performance as measured by the mean asymptote and $95 \%$ confidence limits for total number of arm entries $(\mathrm{p}<0.001)$ and arm entries without error $(\mathrm{p}<0.001)$. Lack of overlap of confidence limits reveals that RAM performance is impaired in apoE-/- mice compared to C57B1/6J mice and HC diet exacerbates impairment only in apoE-/- mice. 